\title{
Coping strategies and self-stigma in patients with schizophrenia-spectrum disorders
}

\author{
This article was published in the following Dove Press journal: \\ Patient Preference and Adherence \\ 24 June 2016 \\ Number of times this article has been viewed
}

\author{
Michaela Holubova ${ }^{1,2}$ \\ Jan Prasko' \\ Radovan Hruby ${ }^{3}$ \\ Klara Latalova' \\ Dana Kamaradova' \\ Marketa Marackova' \\ Milos Slepecky ${ }^{4}$ \\ Terezia Gubova ${ }^{2}$ \\ 'Department of Psychiatry, Faculty \\ of Medicine and Dentistry, Palacký \\ University Olomouc, University \\ Hospital Olomouc, Olomouc, \\ Czech Republic; ${ }^{2}$ Department of \\ Psychiatry, Hospital Liberec, Liberec, \\ Czech Republic; ${ }^{3}$ Private Psychiatric \\ Practice, Martin, Slovak Republic; \\ ${ }^{4}$ Department of Psychology Sciences, \\ Faculty of Social Science and Health \\ Care, Constantine the Philosopher \\ University, Nitra, Slovak Republic
}

Correspondence: Jan Prasko Department of Psychiatry, Faculty of Medicine and Dentistry, Palacký University Olomouc, 8 Kř́žkovského Street, Olomouc 77I47, Czech Republic Email praskojan@seznam.cz
Background: Maladaptive coping strategies may adversely disturb the overall functioning of people with mental disorders. Also, self-stigma is considered a maladaptive psychosocial phenomenon that can affect many areas of patient life. It has a negative impact on self-image, and may lead to dysphoria, social isolation, reduced adherence, using of negative coping strategies, and lower quality of life. The objective of this study was to determine the relationship between coping strategies and self-stigma among persons with schizophrenia and related psychotic disorders.

Subjects and methods: A total of 104 clinically stable outpatients with chronic schizophreniaspectrum disorders were enrolled in a cross-sectional study. Sociodemographic and clinical data were recorded. Patients were examined by psychiatrists with the Stress Coping Style Questionnaire, the Internalized Stigma of Mental Illness scale, and the Clinical Global Impression scale. Correlation and multiple-regression analyses were performed to discover contributing factors to self-stigma.

Results: Positive coping strategies were used by patients with schizophrenia-spectrum disorders to the same extent as in the healthy population. Negative coping strategies were overused by these patients. There were significant associations between self-stigma, severity of the disorder, and coping strategies in schizophrenia. The ability to use positive coping strategies was connected with lower self-stigma. Use of negative coping strategies predominantly increased the self-stigma of patients with schizophrenia.

Conclusion: This study revealed a significant association among self-stigma, severity of the disorder, and coping strategies in individuals suffering from schizophrenia-spectrum disorders. Thinking about coping strategies and self-stigma in practice may play a significant role in understanding people with schizophrenia-spectrum disorders, especially for mental health professionals.

Keywords: self-stigma, coping strategies, schizophrenia, schizoaffective disorder, disorder severity, cross-sectional study

\section{Introduction}

Coping is a psychological process of dealing with the external or internal stress that is reflected as difficult or exceeding a person's resources. As a part of the personal equipment, human coping strategies represent the efforts made by an individual to deal with internal and external stress. ${ }^{1,2}$ The way people cope with stress may affect short-term functioning and long-term adaptation to physical or mental disorders. ${ }^{3}$

It is hard to say what a positive coping strategy is and what a negative coping strategy is. It depends on the context of the situation. The authors of the Stress Coping Style Questionnaire (Stressverarbeitungsfragebogen [SVF]-78 questionnaire) divided coping strategies into positive and negative because of their maladaptive or adaptive potential in solving a stressful situation. ${ }^{4}$ The strategies which are flexible and efficient 
for managing the stress situation, are considered positive. Maladaptive and inflexible strategies are considered to be negative. However, coping strategies are individual and characteristic for each person. The same two strategies used by different people cannot be considered equally positive, because it always depends on the context of the situation and the individual.

The topic of coping in patients with schizophrenia-spectrum disorders remains an area to explore. Coping strategies play a significant role in one's ability to adapt to stressful life conditions, such as schizophrenia. ${ }^{5}$ Life stress plays an important role in the onset and course of schizophrenia-spectrum disorders. Individual dissimilarities in coping strategies and emotional traits, variables associated with the control and experience of stress, may play a significant role in susceptibility to the disorder and symptom exacerbation. ${ }^{6}$ Many patients are highly vulnerable to stressors that can increase the risk for relapse; even in the situation, they are stabilized on medication. ${ }^{7,8}$ Psychological models of psychotic disorders suggest that poor coping responses to stressors play an important role in their pathogenesis. ${ }^{9}$ Specific and general coping strategies may affect well-being, and are closely associated with quality of life. ${ }^{10-12}$

Current studies reveal that individuals with schizophrenia use predominantly maladaptive coping styles., ${ }^{2,13}$ Negative symptoms, subjective quality of life, self-esteem, awareness of symptomatology, and attribution of symptoms to illness are factors enforcing emotion-oriented coping strategies in people with schizophrenia-spectrum disorders. ${ }^{14}$ Avoidance coping strategies are linked to psychological distress, and self-distancing among these patients has been positively related to social diversion, while task-oriented coping style, self-efficacy, perceived social support, and quality of life were lower in comparison to healthy people. ${ }^{13,15,16}$ The enhancement of coping strategies is effective in the treatment of psychotic symptoms. ${ }^{17}$ Evaluating these strategies can be of clinical interest to develop better coping in educational and supportive therapies.

Stigmatization is a psychosocial process that identifies individuals by the negative label of their difference, which is unacceptable for others. ${ }^{18}$ Internalization of stigma is a gradual process of psychological assimilation of the stereotypical attitudes of society by the person. ${ }^{19}$ Self-stigma is associated with lower self-confidence and self-esteem, serious symptoms of illness, less willingness to cooperate in treatment, poorer social and occupational functioning, lower incomes, demoralization, and lower quality of life. ${ }^{20-22}$ Negative self-image leads to passivity, avoidance of friends, resignation to new relationships, and leaving study or employment.
The perceived or experienced stigma is associated with more severe depressive symptoms, greater social anxiety, and avoidant behavior. All of these impacts may be closely associated with the use of specific coping strategies in people with schizophrenia.

Kleim et $\mathrm{al}^{23}$ examined the influence of self-stigma on using negative coping strategies, especially withdrawal from social contact. Kroska and Harkness ${ }^{24}$ found that individuals with schizophrenia reduced negative feelings associated with self-stigma by negative coping strategies, especially by social isolation and withdrawal from society. Chronister et $\mathrm{al}^{25}$ found that individuals who used negative coping strategies of avoidance had a higher degree of self-stigma. These findings suggest that coping strategies in connection with self-stigma may be an important target to reduce.

The objective of the study was to examine the relationships among self-stigma, coping strategies, severity of the disorder, and demographic factors in patients with schizophreniaspectrum disorders. The research hypotheses were:

- positive coping strategies are negatively related to the severity of the disorder

- negative coping strategies are positively related to the severity of the disorder

- positive coping strategies are negatively related to selfstigma

- negative coping strategies are positively related to selfstigma

- the severity of the disorder is positively related to selfstigma.

\section{Subjects and methods}

The research group consisted of mentally ill men and women aged over 18 years diagnosed with schizophrenia and related psychotic disorders, according to the International Classification of Diseases, tenth revision. ${ }^{26}$ The psychiatric outpatients were recruited with the help of collaborating Czech psychiatric outpatient departments from different cities. The research was conducted from March 2014 to November 2015. Inclusion criteria for the patients were the age 18-60 years, signed informed consent, and remission of the disorder. Exclusion criteria were severe acute symptoms, hospitalization, and comorbidity of substance abuse. Patients with acute symptomatology who needed hospitalization or patients with high severity on the Clinical Global Impression (CGI) scale $(>6)$ were not enrolled in the study.

\section{Assessments}

The SVF-78 4 contains 78 items divided into 13 subscales, each demonstrating a certain way of reacting to a stressful 
situation. The SVF-78 has been standardized for the Czech population. ${ }^{4}$ Cronbach's $\alpha$ for the Czech version was between 0.77 and 0.94 . An average use of coping strategies was declared by the authors for subjects with T-scores of 40-60. T-scores higher than 60 indicate higher usage of coping strategies; lower than 40 mean reduced usage of an appropriate strategy. Negative strategies consist of escape tendency, perseveration, resignation, and self-accusation. Positive strategies consist of underestimation, guilt denial, diversion, compensatory satisfaction, situation control, reaction control, positive self-instruction, and need for social support. Only active avoidance, regarded as neutral, is not part of the total score. ${ }^{27}$

The Internalized Stigma of Mental Illness (ISMI) ${ }^{28}$ questionnaire consists of 29 statements with a 4-point scale quantifying the level of agreement. The scale enables assessment of five features of self-stigma: alienation, perceived discrimination, stereotype endorsement, social withdrawal, and resistance to stigma. The questionnaire has been standardized for the Czech population, with an internal consistency defined by Cronbach's $\alpha=0.91 .^{29}$

The $\mathrm{CGI}^{30}$ is a tool for global evaluation of the severity of the disorder based on a 7-point scale ranging from 1 (normal) to 7 (among the most extremely ill patients), based on symptoms, behavior, and functioning over the last 7 days. The CGI objective form (objCGI) is completed by the professional rater. The CGI subjective form (subjCGI) is completed by individuals themselves.

The demographic questionnaire inquired about sex, age, age at onset of the disorder, length of treatment, marital status, employment status, retirement or disability benefits, education, number of past hospitalizations, number of past visited psychiatrists, current medication, withdrawal medication in the past (recommended by a psychiatrist or arbitrary), number of siblings, and positive family history.

\section{Statistical analysis and ethics}

Prism 3 and SPSS 17 were used for statistical analysis. Patients' demographic and clinical characteristics were analyzed using column statistics. The Shapiro-Wilk $W$-test appraised the normality of distribution of the demographic variable, SVF-78, ISMI, and subjCGI/objCGI variables. For analysis of categorical data, the $\chi^{2}$ or Fisher's exact test was used. Score differences were calculated by $t$-tests for paired samples or independent $t$-tests or their nonparametric equivalent (Mann-Whitney $U$-test) in cases of no equal variances with Welch's correction. Interactions between variables with a normal distribution were calculated using Pearson's correlation analysis, while Spearman's rank correlation was used for variables with abnormal distribution. Relationships between multiple factors were analyzed by multiple regressions: a backward-stepwise regression analysis with Bonferroni correction to account for false positives. The level of significance was set at $5 \%$. The ethics committee of the University Hospital Olomouc approved the study. The investigation was conducted in agreement with the latest version of the Helsinki Declaration and standards of good clinical practice. ${ }^{31}$ All participants of the study signed an informed consent.

\section{Results}

\section{Sample description}

A total of 109 patients with psychotic disorders were enrolled in the study. Five dropped out of the study. Therefore, data from 104 individuals were calculated in the statistical analysis. The most frequent diagnosis was schizophrenia $(n=70)$, particularly the paranoid type $(n=61)$, followed by schizoaffective disorder $(n=30)$, acute polymorphic psychotic disorder $(n=2)$, and persistent delusional disorder $(n=2)$. Demographic and clinical data of the sample are presented in Table 1 . The average age of participants was $42.19 \pm 10.09$ years. The onset

Table I Description of the sample of 104 participants: demographic and clinical data

\begin{tabular}{ll}
\hline Variables & $\begin{array}{l}\text { Frequencies and } \\
\text { percentages }\end{array}$ \\
\hline Sex (male:female) & $41: 63$ \\
Education & \\
Elementary & $10(9.6 \%)$ \\
Vocational training & $26(25 \%)$ \\
Secondary school & $51(49 \%)$ \\
University & $16(15.5 \%)$ \\
Marital status & \\
Single & $61(58.7 \%)$ \\
Married & $24(23.1 \%)$ \\
Divorced & $16(15.4 \%)$ \\
Widowed & $1(2.8 \%)$ \\
Employment (yes/no) & $33 / 71$ \\
Retirement & 88 \\
Full disability rent & 61 \\
Partial disability rent & 20 \\
Pension & 7 \\
From a two parent family & 66 \\
From a one parent family & 31 \\
Brothers/sisters (yes/no) & $91 / 13$ \\
Birth order & \\
First-born & 44 \\
Second-born & 37 \\
Third-born & 10 \\
Using psychiatric medication (yes/no) & $102 / 2$ \\
Regular use & 93 \\
Regularly, more than prescribed amount & 2 \\
Irregular use & 7 \\
\hline &
\end{tabular}


of the disorder was at an average age of 26.06 \pm 8.95 years. Mean duration of the illness was $15.67 \pm 9.57$ years, with $4.17 \pm 4.03$ hospitalizations on average.

\section{Treatment}

A total of 102 patients with psychotic spectrum disorders $(98.1 \%)$ reported that they used recommended medication prescribed by an attending psychiatrist. Most used the medication regularly in prescribed doses $(n=93,90.4 \%)$, two patients reported using higher doses than were prescribed $(1.9 \%)$, and seven $(6.7 \%)$ reported using the medication irregularly. Two persons (1.9\%) stated that they did not use the medication at all.

\section{Severity of the disorder}

The actual severity of psychopathology was evaluated by a psychiatrist using the objCGI scores. objCGI was $4.12 \pm 0.95$ on average; this means that psychiatrists assessed the actual severity of their outpatients as moderate-severe on average. The mean score of subjCGI was $2.76 \pm 1.39$. The difference between psychiatrists' and patients' evaluations was $1.67 \pm 1.51$ points. The subjective and objective severity of psychopathology was in positive correlation (Spearman's $r=0.358, P<0.001)$.

\section{Coping strategies}

All 104 participants completed the SVF-78 questionnaire. Negative coping strategies were used to a greater extent than in the healthy population according to $T$-scores, especially the strategies of escape tendency and resignation (Table 2).

Table 2 Mean scores of coping strategies according to SVF-78

\begin{tabular}{ll}
\hline $\begin{array}{l}\text { Coping strategies, } \\
\text { positive/negative }\end{array}$ & $\begin{array}{l}\text { Mean } \pm \text { standard } \\
\text { deviation }\end{array}$ \\
\hline Underestimation & $47.77 \pm 12.57$ \\
Guilt denial & $54.35 \pm 12.2$ \\
Diversion & $50.88 \pm 9.88$ \\
Alternative satisfaction & $55.57 \pm 10.2$ \\
Situation control & $44.95 \pm 11.08$ \\
Reaction control & $47.76 \pm 10.8$ \\
Positive self-instruction & $41.37 \pm 11.95$ \\
Need for social support* & $50.98 \pm 11.02$ \\
Active avoidance* & $55.76 \pm 8.9$ \\
Using positive coping & $49.5 \pm 11.8$ \\
Escape tendency & $61.82 \pm 9.42$ \\
Perseveration & $49.9 \pm 12.5$ \\
Resignation & $60.44 \pm 10.95$ \\
Self-accusation & $53.29 \pm 12.61$ \\
Using negative coping & $59.04 \pm 11.24$ \\
\hline Notes: $*$ Not strictly classified as a positive or negative strategy; depending on the \\
context of the situation and personality, it can acquire both of these qualities. \\
Abbreviation: SVF, Stressverarbeitungsfragebogen (Stress Coping Style Ques- \\
tionnaire).
\end{tabular}

Positive strategies were used at the average level of the healthy population according to $T$-scores (Table 2 ).

\section{Correlation among demographic and clinical variables and coping strategies}

Correlations among individual coping strategies and demographic and clinical variables were examined. A statistically significant association was found between the subjective severity of psychopathology (subjCGI) and coping strategies (Table 3). Positive coping strategies were negatively related to the subjective severity of psychopathology (subjCGI). Individuals who evaluated the severity of the disorder as less severe used positive coping strategies to a greater extent. No significant associations were found among positive coping strategies and age, onset, duration of the disorder, objCGI, number of hospitalizations, or marital status. The analysis suggested a potential relationship between using of positive coping and number of siblings (Table 3).

All of the negative coping strategies (escape tendency, perseveration, resignation, and self-accusation) were positively related to subjCGI score. No association was found among coping strategies and age, duration of the disorder, objCGI, number of hospitalizations, marital status, or number of siblings (Table 3 ).

\section{Self-stigma}

A total of 104 participants completed the ISMI questionnaire. The overall mean score of self-stigma was $64.30 \pm 13.49$. Average scores on each subscale of self-stigma were without

Table 3 Correlations among coping strategies and demographic and clinical variables

\begin{tabular}{llllll}
\hline Domain & Age & Onset & subjCGI & $\begin{array}{l}\text { Marital } \\
\text { status }\end{array}$ & $\begin{array}{l}\text { Number } \\
\text { of siblings }\end{array}$ \\
\hline Underestimation & $0.205^{*}$ & 0.18 & $-0.389^{* * *}$ & $0.217^{*}$ & $0.29^{* *}$ \\
Guilt denial & 0.075 & 0.046 & -0.153 & 0.08 & $0.209^{*}$ \\
Diversion & -0.078 & -0.101 & $-0.279^{* *}$ & -0.092 & $0.28^{* *}$ \\
Compensatory & -0.112 & $-0.234^{*}$ & $-0.25^{*}$ & -0.056 & 0.205 \\
satisfaction & & & & & \\
Reaction control & 0.054 & -0.021 & $-0.246^{*}$ & 0.063 & $0.247^{*}$ \\
Positive self- & 0.038 & -0.01 & $-0.39^{* * *}$ & 0.104 & $0.314^{* *}$ \\
instruction & & & & & \\
Escape tendency & -0.007 & -0.061 & $0.38^{* * *}$ & -0.04 & -0.007 \\
Perseveration & -0.13 & $-0.253^{* *}$ & $0.298^{* *}$ & -0.167 & -0.073 \\
Resignation & -0.07 & -0.091 & $0.488^{* * *}$ & -0.088 & -0.102 \\
Self-accusation & -0.021 & -0.137 & $0.318^{* *}$ & -0.07 & -0.091 \\
Negative coping & -0.092 & -0.189 & $0.436^{* * *}$ & -0.12 & -0.093 \\
Positive coping & 0.032 & -0.04 & $-0.346^{* *}$ & 0.06 & $0.302^{* *}$ \\
\hline Notic
\end{tabular}

Notes: $* P<0.05 ; * * P<0.01 ; * * * P<0.001$; Pearson and Spearman correlations. Abbreviation: subjCGl, subjective (patient) evaluation of Clinical Global Impression. 
Table 4 Correlations among self-stigma and demographic and clinical variables

\begin{tabular}{lllllll}
\hline Variables & $\begin{array}{l}\text { Overall ISMI } \\
\text { score }\end{array}$ & Alienation & $\begin{array}{l}\text { Stereotype } \\
\text { agreement }\end{array}$ & $\begin{array}{l}\text { Perceived } \\
\text { discrimination }\end{array}$ & $\begin{array}{l}\text { Social } \\
\text { withdrawal }\end{array}$ & $\begin{array}{l}\text { Stigma } \\
\text { resistance }\end{array}$ \\
\hline Onset & -0.125 & -0.188 & -0.068 & $-0.274^{*}$ & -0.092 & 0.087 \\
Length & $0.181(P=0.06)$ & $0.19^{*}$ & 0.163 & $0.188(P=0.052)$ & 0.163 & 0.048 \\
Hospitalizations & 0.121 & 0.143 & 0.011 & $0.277^{* *}$ & 0.139 & -0.091 \\
objCGI & 0.154 & 0.072 & 0.103 & $0.211^{*}$ & 0.136 & 0.149 \\
subjCGI & $0.52^{* * *}$ & $0.466^{* * *}$ & $0.475^{* * *}$ & $0.319^{* * *}$ & $0.482^{* * *}$ & $0.339 * * *$ \\
objCGI - subjCGI & $-0.374^{* * *}$ & $-0.375^{* * *}$ & $-0.338^{* *}$ & $-0.209 *$ & $-0.363^{* * *}$ & -0.138 \\
\hline
\end{tabular}

Notes: $* P<0.05 ; * * P<0.01$; $* * * P<0.001$; Pearson and Spearman correlations.

Abbreviations: ISMI, Internalized Stigma of Mental Illness; objCGI, objective (clinician) evaluation of Clinical Global Impression; subjCGI, subjective (patient) evaluation of CGI.

significant differences. Individuals with schizophrenia scored highest in the subscale Agreement with stereotypes

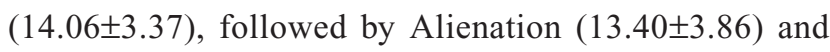
Social withdrawal (13.11 \pm 3.69$)$. The Perceived discrimina-

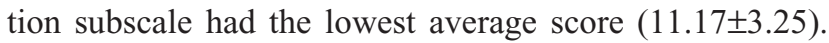
On the Stigma resistance subscale, participants achieved on average $12.67 \pm 2.36$ points.

\section{Correlations between self-stigma and demographic and clinical variables}

There were no statistically significant correlations between overall ISMI score and age, number of hospitalizations, objective evaluation of severity of disorder, duration of disease, or onset of disorder (Table 4).

However, the onset of the disorder correlated negatively with the ISMI subscale Perceived discrimination (Table 4), such that if the mental disorder started at an earlier age, patients with schizophrenia perceived a higher intensity of discriminative behavior from others. The same conclusion can be applied to the ISMI subscale Perceived discrimination and number of hospitalizations, where a positive correlation was detected. Also, a positive correlation was found between the length of the disorder and the ISMI subscale
Alienation, (longer duration of illness could be related to socially alienated feelings) (Table 4).

A statistically significant positive correlation was found between self-stigma and the current severity of the disorder evaluated by participants (subjCGI). Patients with schizophrenia who evaluated their disorder as more severe rated themselves more highly on all the ISMI subscales (Table 4). objCGI severity did not correlate with overall ISMI score.

No differences were found among sex, marital status, level of education, and the overall ISMI score $=($ Table 4$)$. A statistically significant difference was detected between the overall ISMI score and employment. Individuals who had a job $(n=33)$ stigmatized themselves less than jobless patients with schizophrenia $(\mathrm{n}=75)$ (Table 4).

\section{Correlation between self-stigma and coping strategies}

Self-stigma was significantly associated with negative coping strategies. Participants who used negative coping had higher levels of self-stigma (Table 5). All negative strategies correlated positively with the separate subscales of ISMI, except strategy perseverance and the ISMI subscale Stigma resistance. Only the positive strategy need for social support

Table 5 Correlations among self-stigma and coping strategies

\begin{tabular}{|c|c|c|c|c|c|c|}
\hline Coping strategies & $\begin{array}{l}\text { Whole } \\
\text { score }\end{array}$ & Alienation & $\begin{array}{l}\text { Stereotype } \\
\text { agreement }\end{array}$ & $\begin{array}{l}\text { Perceived } \\
\text { discrimination }\end{array}$ & $\begin{array}{l}\text { Social } \\
\text { withdrawal }\end{array}$ & $\begin{array}{l}\text { Stigma } \\
\text { resistance }\end{array}$ \\
\hline Underestimation & $-0.424 * * *$ & $-0.397 * * *$ & $-0.3^{* *}$ & $-0.282 * *$ & $-0.459 * * *$ & $-0.219 *$ \\
\hline Guilt denial & $-0.256 * *$ & -0.149 & $-0.317 * *$ & -0.152 & $-0.226 *$ & $-0.26 I^{* *}$ \\
\hline Diversion & $-0.365 * * *$ & $-0.3 I^{* *}$ & $-0.336 * *$ & $-0.254^{*}$ & $-0.276 * *$ & $-0.363^{* * *}$ \\
\hline Compensatory satisfaction & $-0.223^{*}$ & -0.089 & $-0.233^{*}$ & -0.132 & -0.165 & $-0.294^{* *}$ \\
\hline Situation control & $-0.219 *$ & $-0.202^{*}$ & $-0.218^{*}$ & -0.103 & -0.133 & $-0.263^{* *}$ \\
\hline Reaction control & $-0.377 * * *$ & $-0.337 * * *$ & $-0.385^{* * *}$ & $-0.313^{* *}$ & $-0.3^{* *}$ & $-0.265^{* *}$ \\
\hline Positive self-instruction & $-0.555 * * *$ & $-0.464 * * *$ & $-0.52 I^{* * *}$ & $-0.322 * *$ & $-0.447 * * *$ & $-0.468 * * *$ \\
\hline Positive coping & $-0.491 * * *$ & $-0.399 * * *$ & $-0.464 * * *$ & $-0.315^{* * *}$ & $-0.406 * * *$ & $-0.43 I^{* * *}$ \\
\hline Escape tendency & $0.434^{* * *}$ & $0.428 * * *$ & $0.27 \mid * *$ & $0.236^{*}$ & $0.375 * * *$ & $0.303 * *$ \\
\hline Perseveration & $0.436 * * *$ & $0.504 * * *$ & $0.28 I^{*}$ & $0.345^{* * *}$ & $0.456 * * *$ & 0.148 \\
\hline Resignation & $0.637 * * *$ & $0.631 * * *$ & $0.485^{* * *}$ & $0.388^{* * * *}$ & $0.57 * * *$ & $0.403^{* * *}$ \\
\hline Self-accusation & $0.454 * * *$ & $0.494 * * *$ & $0.38 I^{* * *}$ & $0.266^{* * *}$ & $0.417 * * *$ & $0.194^{*}$ \\
\hline Negative coping & $0.598 * * *$ & $0.632 * * *$ & $0.412 * * *$ & $0.386 * * *$ & $0.57 * * *$ & $0.28 * *$ \\
\hline
\end{tabular}

Notes: $* P<0.05 ; * * P<0.01$; $* * * P<0.001$; Pearson correlations. 
Table 6 First model of stepwise-regression analysis of ISMI and selected factors

\begin{tabular}{lllll}
\hline Regressors & B & SE & $\beta$ & Significance \\
\hline Negative coping strategies & 1.908 & 0.255 & 0.619 & $P<0.001$ \\
subjCGI & 3.63 & 0.822 & 0.367 & $P<0.001$ \\
Positive coping strategies & -1.006 & 0.328 & -0.247 & $P<0.01$
\end{tabular}

Abbreviations: ISMI, Internalized Stigma of Mental IIIness; SE, standard error; subjCGI, subjective (patient) evaluation of Clinical Global Impression.

and the neutral strategy active avoidance did not correlate with the total ISMI score or ISMI subscales.

Self-stigma was also significantly negatively associated with positive coping strategies. Patients who used positive strategies more experienced lower self-stigma. Underestimation, diversion, reaction control, and positive self-instruction negatively correlated with all ISMI subscales. The strategy of positive self-instruction was significantly negatively associated with ISMI (Table 5).

\section{Regression analysis}

Statistical analysis showed significant correlations among selfstigma, coping strategies, and current levels of psychopathology. Stepwise-regression analysis detected the proportion of single factors contributing to self-stigma. As the first step, the relationships among overall ISMI score (dependent variable), negative and positive coping strategies, demographic and clinical variables, and objCGI/subjCGI evaluation of the actual severity of psychopathology were investigated. The strongest predictors that influenced overall ISMI score were negative coping strategies $(\beta=0.615)$, then subjCGI $(\beta=0.364)$ and positive coping strategies $(\beta=-0.261)$. The regression model for all of these three variables explained $52.8 \%$ of the overall score variance of the ISMI ( $F=9.436, P<0.01)$ (Table 6).

The second model of stepwise-regression analysis was used to analyze single coping strategies that correlated with ISMI (therefore without need for social support and active avoidance), demographic and clinical variables, objCGI, subjCGI, and the difference between objCGI and subjCGI. The most significant factor connected with self-stigma was the negative strategy resignation $(\beta=0.665)$, then subjCGI $(\beta=0.312)$ and the positive strategy positive self-instruction $(\beta=-0.233)$. The model of these three variables explained $53.6 \%$ of overall ISMI variance $(F=6.899, P<0.05)$ (Table 7).

\section{Discussion}

This study examined whether patients with schizophreniaspectrum disorders use positive coping strategies to the same extent as the healthy population according to $T$-scores
Table 7 Second model of stepwise-regression analysis of ISMI and selected factors

\begin{tabular}{lllll}
\hline Regressors & B & SE & $\beta$ & Significance \\
\hline Positive self-instruction & 7.34 & 3.927 & $0.63 \mathrm{I}$ & $P<0.00 \mathrm{I}$ \\
objCGI & -23.818 & 5.242 & 0.384 & $P<0.0 \mathrm{I}$ \\
objCGI - subjCGI & 10.579 & $\mathrm{I} .183$ & 0.252 & $P<0.05$ \\
\hline
\end{tabular}

Abbreviations: ISMI, Internalized Stigma of Mental IIIness; SE, standard error; objCGI, objective (clinician) evaluation of Clinical Global Impression; subjCGI, subjective (patient) evaluation of Clinical Global Impression.

established by authors of the questionnaire. ${ }^{4}$ What was surprising was that patients had a moderate level of symptomatology according to their psychiatrists, so the objective severity of psychopathology probably did not decrease the use of positive coping. Patients with schizophrenia overused negative coping strategies in comparison with $T$-scores of the healthy population. This result was in agreement with those of Kleim et al, ${ }^{23}$ Kroska and Harkness,${ }^{24}$ and Chronister et al. ${ }^{25}$ Some authors believe that patients use negative coping strategies to reduce negative feelings connected to self-stigma, ${ }^{24}$ mainly the social isolation. ${ }^{23,25}$

The results of our study also showed an association between the subjective severity of psychopathology and coping strategies. This finding can be explained by people feeling severely mentally ill (regardless of objective seriousness) using negative coping strategies (escape tendencies and resignation) to a greater extent, such that they may have resigned themselves to the possibility of never finding a solution to their situation. Patients who evaluated the severity of their disorder as less severe used more positive coping strategies to a greater extent. These results confirmed our first two hypotheses.

It is interesting that the objective severity of psychopathology assessed by a physician did not have a significant impact on the use of coping strategies. Surprisingly, no correlation between self-stigma and objective evaluation of the severity of the disorder was found, but subjective evaluation of patients played an important role in perception of self-stigma. Patients assessed themselves as less seriously ill than their physicians did. This reflects the common problem of lack of insight in schizophrenia patients. It seems that lower evaluation of the severity of the disorder by patients is connected with lower self-stigma, because patients feel healthier and have less reason to agree with stereotypes about mentally ill people, as they do not feel mentally ill. This is in accordance with our hypothesis, that the severity of the disorder is positively related to self-stigma.

The results also showed that men and women with schizophrenia did not differ in use of positive and negative 
coping strategies. Sex differences did not play an important role. Based on previous studies in healthy populations, we expected the opposite. ${ }^{32,33}$ No difference was found between patients with different levels of education and coping strategies. This may be related to the assumption that coping strategies are acquired behaviors related to personal characteristics of a person. It seems that formal education does not preclude the use of coping strategies in people with schizophrenia.

According to our findings, using positive coping strategies should be associated with the number of siblings, especially the strategies of underestimation of the seriousness of the situation and positive self-instruction. Patients with a larger number of siblings could probably support themselves to a greater extent than patients without siblings, and do not experience the situation so dramatically because of more requirements for self-assertion, observational learning/ solving problems, or gaining a wider repertoire of possible coping strategies. These findings could play a significant role in thinking about coping strategies, but this should also be a random association that results from cross-sectional study.

The most important finding was that use of positive coping strategies was related to lower levels of self-stigma. This confirmed our hypothesis that positive coping strategies are negatively related to self-stigma. The results also showed that patients with schizophrenia-spectrum disorders who used negative coping strategies to a greater extent tended to stigmatize themselves more, especially when they used escape tendencies, resignation, and self-accusation. This confirmed our hypothesis that negative coping strategies are positively related to self-stigma. These results corresponded with those of Kleim et al, ${ }^{23}$ such that use of negative coping had the effect of stigma and social withdrawal. Therefore, the reduction of negative coping strategies in treatment can be used to help in self-stigma reduction and vice versa. It could be important to look for approaches that reduce self-stigma and help to remove excessive avoidance behavior.

The regression analysis showed the influence of coping strategies (especially negative coping) and subjective evaluation of the severity of the disorder on self-stigma. These results may indicate an important finding that patients who feel seriously mentally ill were rather resigned to their situation and self-stigmatized more. However, patients who were able to appreciate and support themselves using positive selfinstruction did not feel self-stigma so much. However, this model explained almost $53 \%$ of the variance of self-stigma, so the influence of unidentified variables in this study may have played an important role as well.

\section{Limitations}

The main limitation of the study was the use of self-report scales and questionnaires. These questionnaires can be significantly affected by the current state of the patients, their willingness to be open in their statements, and by cognitive deficits. Many questions in the questionnaires can cause participants not to be attentive at the end of filling them out. Also, the severity of illness was assessed by global clinical evaluation only, using no symptom specific objective assessment instruments. The research used a small sample size. There was no possibility of determining causality among self-stigma, coping strategies, and the severity of the disorder, because of the cross-sectional design of the study. Nevertheless, the results highlighted the importance of the topic of coping strategies and self-stigma in people with schizophrenia-spectrum disorders.

\section{Conclusion}

Thinking about coping strategies and self-stigma in practice may play a significant role in understanding people with schizophrenia-spectrum disorders, especially for mental health professionals. Focus on the reduction of negative coping strategies or self-stigma in the form of supportive and psychoeducation strategies could be a useful concept in the therapy of patients with schizophrenia-spectrum disorders. The development of more adaptive coping strategies could be an important part of effective treatment of psychotic symptoms and reduction of self-stigma in patients.

\section{Acknowledgments}

For their willing cooperation, we thank engineer Miloš Čejka from Hradec Králové, Václav Holub from Liberec, Dr Jiří Rozkoš from Prostějov, Dr Jan Flídr from Kralupy nad Vltavou, Dr Jana Matějková from Prague, Dr Simona Papežové from Prague, Dr Pavel Tautermann from Prague, Dr Markéta Zemanová from Havlíčkův Brod, Dr Markéta Dobrá from Hrabyně, Dr Zuzana Kozáková from Trutnov (association RIAPS), Dr Tibor Miklóš from Prague, Dr Michaela Zapletalová from Chomutov, Dr Jana Novosadová from Blansko, Dr Jiří Trska from Týn nad Vltavou, Dr Zdeněk Holoubek from Nymburk, Dr Iva Ondráčková from Prague, Dr Andrea Bryčková from Hořice, Dr Jindřiška Masnerová from Beroun, Dr Petr Pastucha from Prostějov, and Dr Hana Lemanová from Brno.

\section{Disclosure}

The authors report no conflicts of interest in this work. 


\section{References}

1. Křivohlavý J, editor. Jak zvládat stres [How to cope with stress]. Prague: Grada; 1994. Czech.

2. Marquez-Arrico JE, Benaiges I, Adan A. Strategies to cope with treatment in substance use disorder male patients with and without schizophrenia. Psychiatry Res. 2015;228:752-759.

3. Skinner EA, Edge K, Altman J, Sherwood H. Searching for the structure of coping: a review and critique of category systems for classifying ways of coping. Psychol Bull. 2003;129:216-269.

4. Janke W, Erdmann G. SVF 78: Eine Kurzform des Stressverarbeitungsfragebogen SVF 120 [A short form of stress management questionnaire SVF 120]. Göttingen: Hogrefe Verlag für Psychologie; 2002. German.

5. Strous RD, Ratner Y, Gibel A, Ponizovsky A, Ritsner M. Longitudinal assessment of coping abilities at exacerbation and stabilization in schizophrenia. Compr Psychiatry. 2005;46:167-175.

6. MacAulay R, Cohen AC. Affecting coping: does neurocognition predict approach and avoidant coping strategies within schizophrenia spectrum disorders? Psychiatry Res. 2013;209:136-141.

7. Nuechterlein KH, Dawson M, Gitlin M, et al. Developmental processes in schizophrenic disorders: longitudinal studies of vulnerability and stress. Schizophr Bull. 1992;18:387-425.

8. Vaughan C, Leff $\mathrm{J}$. The influence of family and social factors on the course of psychiatric illness: a comparison of schizophrenic and depressed neurotic patients. Br J Psychiatry. 1976;129:125-137.

9. Phillips LJ, Francey SM, Edwards J, McMurray N. Strategies used by psychotic individuals to cope with life stress and symptoms of illness: a systematic review. Anxiety Stress Coping. 2009;22:371-410.

10. Brenner K, St-Hilaire A, Liu A, Laplante DP, King S. Cortisol response and coping style predict the quality of life in schizophrenia. Schizophr Res. 2011;128:23-29.

11. Holubova M, Prasko J, Hruby R, et al. Coping strategies and quality of life in schizophrenia: a cross-sectional study. Neuropsychiatr Dis Treat. 2015;11;3041-3048.

12. Sheshtawy EA. Coping with stress and quality of life in schizophrenic patients. Asian J Psychiatr. 2011;4:51-54.

13. Cotton SM, McCann TV, Gleeson JF, Crisp K, Murphy BP, Lubman DI. Coping strategies in carers of young people with a first episode of psychosis. Schizophr Res. 2013;146:118-124.

14. Zappia S, Montemagni C, Macrì A, Sandei L, Sigaudo M, Rocca P. [Coping styles in schizophrenia: a study of clinical and functional variables as determinants of strategies to cope with stress]. Riv Psichiatr. 2012;47:238-245. Italian.

15. Ponizovsky AM, Finkelstein I, Poliakova I, Mostovoy D, Goldberg N, Rosca P. Interpersonal distances, coping strategies and psychopathology in patients with depression and schizophrenia. World J Psychiatry. 2013;3:74-84.

16. Ritsner MS, Gibel A, Ponizovsky AM, Shinkarenko E, Ratner Y, Kurs R. Coping patterns as a valid presentation of the diversity of coping responses in schizophrenia patients. Psychiatry Res. 2006;144: $139-152$.

17. Rückl S, Gentner NC, Büche L, et al. Coping with delusions in schizophrenia and affective disorder with psychotic symptoms: the relationship between coping strategies and dimensions of delusion. Psychopathology. 2015;48:11-17.
18. Switaj P, Chrostek A, Grygiel P, Wciórka J, Anczewska M. Exploring factors associated with the psychosocial impact of stigma among people with schizophrenia or affective disorders. Community Ment Health J. 2016;52:370-378.

19. Ocisková M, Praško J, Kamarádová D, et al. Self-stigma in psychiatric patients: standardization of the ISMI scale. Neuro Endocrinol Lett. 2014;35:624-632.

20. Perlick DA, Rosenheck RA, Clarkin JF, et al. Stigma as a barrier to recovery: adverse effects of perceived stigma on social adaptation of persons diagnosed with bipolar affective disorder. Psychiatr Serv. 2001; 52:1627-1632.

21. Yanos PT, Roe D, Markus K, Lysaker PH. Pathways between internalized stigma and outcomes related to recovery in schizophrenia spectrum disorders. Psychiatr Serv. 2008;59:1437-1442.

22. Brohan E, Slade M, Clement S, Thornicroft G. Experiences of mental illness stigma, prejudice and discrimination: a review of measures. BMC Health Serv Res. 2010;10:80.

23. Kleim B, Vauth R, Adam G, Stieglitz R, Hayward P, Corrigan P. Perceived stigma predicts low self-efficacy and poor coping in schizophrenia. J Ment Health. 2008;17:482-491.

24. Kroska A, Harkness S. Coping with the stigma of mental illness: empirically-grounded hypotheses from computer simulations. Soc Forces. 2011;89:1315-1339.

25. Chronister J, Chou CC, Liao HY. The role of stigma coping and social support in mediating the effect of societal stigma on internalized stigma, mental health recovery, and quality of life among people with serious mental illness. J Community Psychol. 2013;41:582-600.

26. World Health Organization. The ICD-10 classification of Mental and Behavioural Disorders: Diagnostic Criteria for Research. Geneva: WHO; 1993.

27. Svancara J, editor. Coping Strategies. Prague: Testcentrum; 2003.

28. Ritsner M, Ben-Avi I, Ponizovsky A, Timinsky I, Bistrov E, Modai I. Quality of life and coping with schizophrenia symptoms. Qual Life Res. 2003;12:1-9.

29. Ociskova M, Prasko J, Kamaradova D, et al. Self-stigma in psychiatric patients: standardization of the ISMI scale. Neuro Endocrinol Lett. 2014;35:624-632.

30. Guy W. ECDEU Assessment Manual for Psychopharmacology. Rockville (MD): US Department of Health, Education, and Welfare; 1976.

31. World Medical Association. WMA Declaration of Helsinki - Ethical Principles for Medical Research Involving Human Subjects. FerneyVoltaire, France: WMA; 2013. http://www.wma.net/en/30publications/ 10policies/b3. Accessed October 19, 2013

32. Jiang Y, Sun YF, Yang YB, et al. Gender differences in coping styles of Chinese military officers undergoing intensive training. Mil Psychol. 2013;25:124-135.

33. Paulík K, editor. Psychologické Aspekty Zvládáni Zátěže Muži a Ženami [Psychological Aspects of Coping between men and women]. Ostrava: Ostravská Univerzita; 2012
Patient Preference and Adherence

\section{Publish your work in this journal}

Patient Preference and Adherence is an international, peer-reviewed, open access journal that focuses on the growing importance of patient preference and adherence throughout the therapeutic continuum. Patient satisfaction, acceptability, quality of life, compliance, persistence and their role in developing new therapeutic modalities and compounds to optimize

\section{Dovepress}

clinical outcomes for existing disease states are major areas of interest for the journal. This journal has been accepted for indexing on PubMed Central. The manuscript management system is completely online and includes a very quick and fair peer-review system, which is all easy to use. Visit http://www. dovepress.com/testimonials.php to read real quotes from published authors. 